\title{
Psychology and the Leadership Void: A Call for Formal Leadership Development
}

\author{
Keith Klostermann ${ }^{1 *}$, Susan Steffan ${ }^{2}$, William Weeks ${ }^{2}$ and Theresa Mignone ${ }^{3}$ \\ ${ }^{1}$ Department of Psychology, Medaille College, USA \\ ${ }^{2}$ Department of Business, Management, Leadership, Medaille College, USA \\ ${ }^{3}$ Department of Psychology, VA Western New York Healthcare System, USA \\ *Corresponding author: Keith Klostermann, Department of Psychology, Medaille College, 18 Agassiz Circle, Buffalo, NY 14214, USA
}

Submission: 眥 February 26, 2018; Published: 啙April 11, 2018

\section{Editorial}

Across multiple disciplines, strong organizational leadership is considered an essential feature of successful organizations. While the importance of effective leadership on micro and macro level outcomes has been recognized within many disciplines (e.g., business and industry, military), the mental health and psychology fields have historically neglected the traditional aspects of leadership. These fields have instead either de-valued the role of leadership training (either intentionally or unintentionally) or relied on several faulty assumptions related to leadership development. Moreover, the lack of appropriate selection mechanisms for identifying qualified leadership candidates has resulted in a void of leadership and a failure to promote and foster professional growth that would turn the most talented individuals into successful leaders. Although on the surface this may seem like an academic exercise, the lack of effective leadership in psychology and mental health has important implications for service delivery and patient care as well as therapist morale, professional development, and burnout. Moreover, poor leadership has a negative impact on the recruitment of highly trained therapists and retention of top performers.

The leadership vacuum may be, in part, based on several faulty assumptions including that experience is synonymous with leadership, and that visibility outweighs qualifications. There also exists insecurity among many decision-makers that can prevent the hiring of highly skilled leaders, a general lack of accountability and leadership understanding at the hiring level, and active inertia. If one of the defining qualities of leadership is to discover and capture the collective genius potentially found in any organization, then these faulty assumptions sub-optimize the potential of any organization. Leaders need to be the intellectual caretakers of their organizations as well as their organizational architects.

The mental health and psychology fields could improve outcomes for patients and job satisfaction for caregivers by applying the leadership development emphasis that has helped propel so many business and military organizations to success. A leader inspires the people around them to believe in their cause and push their boundaries. Professionals in any organization need to know why what they do matters, be given the tools they need to do their jobs well, and trust that those in leadership positions have the skill set to lead.

In disciplines as fluid and dynamic as mental health and psychology, it is imperative that organizations take on both a collaborative and growth mindset to provide an environment that supports acquisition and application of new knowledge. Individuals who are a part of a true learning organization feel as if they are a part of something greater than themselves; that they are members of a productive team. The environment of a learning organization must allow time for (and be supportive of) reflection and analysis, with open boundaries and free flowing information. Simply stated, learning organizations must provide an environment that is conducive to learning. This learning environment concept is particularly timely given the results of recent studies demonstrating the importance of engaging in intentional self-reflection focused on therapist growth edges and using deliberate practice activities as a mechanism for improving therapist effectiveness and enhancing professional growth and development over time.

The lack of strong and effective organizational and systemic leadership has important consequences for the quality of patient care, individual and professional growth (and retention) of therapists, and ultimately the continued evolution of the field. The mental health and psychology fields need to study and promote leadership in an intentional, patient-centered manner to build the strongest organizations, capable of producing superior outcomes for patients. Formal leadership training should be required of therapists looking to expand from their practitioner role, and evaluation of their leadership skill set, not just their functional skills, should be used when making promotional decisions. 
Creative Commons Attribution 4.0 International License

For possible submissions Click Here

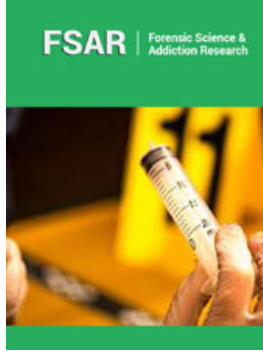

\section{Forensic Science \& Addiction Research}

\section{Benefits of Publishing with us}

- High-level peer review and editorial services

- Freely accessible online immediately upon publication

- Authors retain the copyright to their work

- Licensing it under a Creative Commons license

- Visibility through different online platforms 